\title{
In-Vitro Comparative Adhesion Evaluation of Bioceramic and Dual-Cure Resin Endodontic Sealers Using SEM, AFM, Push-Out and FTIR
}

\author{
Radu Marcel Chisnoiu ${ }^{1}$, Marioara Moldovan ${ }^{2}{ }^{(0}$, Doina Prodan ${ }^{2}{ }^{(0}$, Andrea Maria Chisnoiu ${ }^{3, *}$, Dana Hrab ${ }^{1}$, \\ Ada Gabriela Delean ${ }^{1}$, Alexandrina Muntean ${ }^{4}$, Doina Iulia Rotaru ${ }^{1}$, Ovidiu Pastrav ${ }^{1}$ and Mihaela Pastrav ${ }^{5}$
}

check for updates

Citation: Chisnoiu, R.M.; Moldovan, M.; Prodan, D.; Chisnoiu, A.M.; Hrab, D.; Delean, A.G.; Muntean, A.; Rotaru, D.I.; Pastrav, O.; Pastrav, M. In-Vitro Comparative Adhesion Evaluation of Bioceramic and Dual-Cure Resin Endodontic Sealers Using SEM, AFM, Push-Out and FTIR. Appl. Sci. 2021, 11, 4454. https://doi.org/10.3390/app11104454

Academic Editor: Giovanni Bruno

Received: 18 April 2021

Accepted: 11 May 2021

Published: 13 May 2021

Publisher's Note: MDPI stays neutral with regard to jurisdictional claims in published maps and institutional affiliations.

Copyright: (c) 2021 by the authors. Licensee MDPI, Basel, Switzerland. This article is an open access article distributed under the terms and conditions of the Creative Commons Attribution (CC BY) license (https:// creativecommons.org/licenses/by/ $4.0 /)$.
1 Department of Odontology, Endodontics and Oral Pathology, "Iuliu Hatieganu” University of Medicine and Pharmacy, 33 Motilor Street, 400001 Cluj-Napoca, Romania; marcel.chisnoiu@umfcluj.ro (R.M.C.); dana.hrab@umfcluj.ro (D.H.); ada.delean@umfcluj.ro (A.G.D.); doina.rotaru@umfcluj.ro (D.I.R.); ovidiu.pastrav@umfcluj.ro (O.P.)

2 Department of Polymeric Composites, "Raluca Ripan" Institute of Research in Chemistry, "Babes Bolyai" University, 30 Fantanele Street, 400294 Cluj-Napoca, Romania; marioara.moldovan@ubbcluj.ro (M.M.); doina.prodan@ubbcluj.ro (D.P.)

3 Department of Prosthodontics, "Iuliu Hatieganu" University of Medicine and Pharmacy, 32 Clinicilor Street, 400006 Cluj-Napoca, Romania

4 Department of Pedodontics, "Iuliu Hatieganu” University of Medicine and Pharmacy, 31 Avram Iancu Street, 400083 Cluj-Napoca, Romania; alexandrina.muntean@umfcluj.ro

5 Department of Orthodontics, "Iuliu Hatieganu" University of Medicine and Pharmacy, 31 Avram Iancu Street, 400083 Cluj-Napoca, Romania; mihaela.pastrav@umfcluj.ro

* Correspondence: maria.chisnoiu@umfcluj.ro; Tel.: +40-745759592

\begin{abstract}
Background: Which are the adhesion characteristics of four root canal sealers: two experimental (dual cure resin based endodontic sealer (E1-DCR) and bioceramic based sealer (E2-BC)), and two commercial (RealSeal and TotallFill BC (FKG Germany)). (2) Methods. One-hundred-twenty extracted monoradicular teeth received mechanic-antiseptic preparation and then endodontic filling using gutta-percha in combination with one of the four sealers. Samples from the apical third were selected from each tooth and were randomly distributed for Scanning Electron Microscopy (SEM), Atomic Force Microscopy (AFM) and push-out bond strength. Fourier Transform Infrared (FTIR) Spectroscopy was made exclusively for experimental sealers. (3) Results. The two experimental materials did not present a significant difference in apical sealing ability based on SEM evaluation. Gaps were identified in case of RealSeal samples and also lower penetration into the dentinal tubules compared to TotalFill BC. On AFM analysis a more pronounced penetration into the tubules was observed in case of E2-BC sealer was observed. E1-DCR registered a lower bond strength $(0.7177 \pm 0.55)$ in the apical third compared to Total Fill BC $(p=0.01)$. (4) Conclusions. Within the limitations of the current study, it can be stated that the two experimental sealers' characteristics are comparable to that of the two consecrated materials.
\end{abstract}

Keywords: bioceramic; dual cure resin; endodontic sealer; adhesion

\section{Introduction}

Achieving an ideal adhesion is a real challenge due to the geometry of the radicular system and the necessity to reduce stress during and after material setting [1-3]. Resin infiltration into the partially demineralized collagen matrix is an important factor for mechanical micro retention. Self-etch and self-bond sealants must be sufficiently aggressive to overpass the smear-layer and to demineralize the denting, creating mechanical micro retentions [4]. Sealers' acidity can also be reduced by mineral components of the smearlayer $[5,6]$. Incertitude has appeared regarding the efficiency of self-adhesive sealers [7] and the need of preconditioning dentinal surfaces for superior adhesion has been indicated [8]. 
There is a great variety of materials used in endodontic practice and the newly developed bioceramic-based root canal sealers have improved physicochemical properties (biocompatibility, lack of toxicity and grip contraction, chemical stability). In endodontics, bioceramic-based materials do not cause a significant inflammatory response in case of excessive apical extrusion. Another advantage is the ability to form hydroxyapatite (during adhesion) and bond to dental tissues (dentin). Superior adjustment to the upper walls is also due to its hydrophilic nature. The bioceramic sealers can penetrate into the dentinal tubules and polymerize, forming a hybrid layer. The formation of the hybrid layer is favored by the existence of hydrophilic monomers and solvent in the bioceramic sealer composition [9]. The adhesion of bioceramic root canal sealers consists in hydrated calcium silicate powder that results in calcium silicate hydrate gel and calcium hydroxide [10].

Endodontic filling using urethane dimethacrylate resin is claimed to create a tight seal with the dentinal tubules within the root canal system. In essence, it produces a "monoblock" effect, where the core material, sealer and dentinal tubules become a single solid structure [11]. The introduction of a new dual cure resin based self-etch root canal filling material with similar bond strength to dentin and with a biocompatible polymer matrix has proven promising in what concerns the design of new materials for various applications in endodontic [6-15].

Scanning electron microscopy is one of the first and most used methods for the study of mechanism implied in the adhesion process. Using SEM micrographs, surface details regarding corrosion and resin infiltration into dentinal tubules can be investigated [16-19].

Atomic force microscopy (AFM) is an important tool for biological sample evaluation due to its surface evaluation capacity in liquid environment. Currently this is the only available technique that directly provides structural, mechanical and functional information on high resolution [20].

The push-out test provides a better assessment of adhesion than conventional shear tests, because the fracture takes place in parallel with the dentin-cement interface, which makes a true shear test with the parallel sides of the samples. It has the advantage that it more closely simulates the clinical condition [21-23].

We have developed an in vitro comparative study in order to evaluate the formation of the hybrid layer and sealant infiltration in radicular tubules for: an experimental dual cure resin based endodontic sealer (E1-DCR), an experimental bioceramic based sealer (E2-BC), compared to two commercial widespread resin-based material (Real Seal and TotalFill BC (FKG Germany)) using SEM and AFM analysis. The interfacial forces and filling defects in the root canals were evaluated using push-out bond strength. In order to study the interaction between the two experimental endodontic materials and the biological environment a Fourier Transform Infra-Red (FTIR) Spectroscopy analysis was performed.

\section{Materials and Methods}

A total of 120 single-rooted extracted human premolars with straight, fully formed roots, a single canal and no previous endodontic treatment were used. Caries absence, linear roots and mature apex without pathological modifications also represented inclusion criteria. The teeth were prepared to working length using an F2 ProTaper instrument (Dentsply Maillefer) in continuous rotation. They were randomly divided into 4 groups as presented in Figure 1.

Teeth were extracted due to orthodontic or periodontal indication with maximum 4 weeks prior to study beginning. Digital x-rays under two incidences were performed for group uniformity, all teeth with internal root resorbtions, calcifications, fractures and teeth with more than one canal per root being eliminated from the study. 


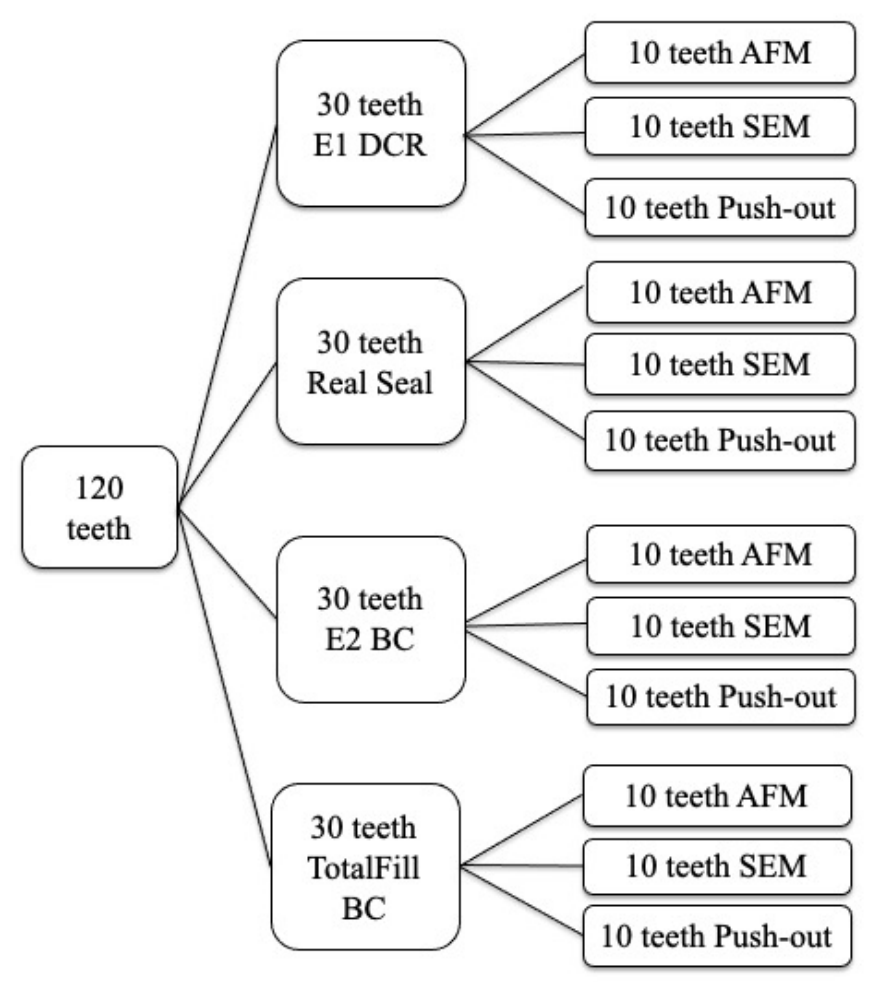

Figure 1. Sample distribution for SEM, AFM and Push-out study.

Mechanical-antiseptic preparation of the root canals. The teeth were prepared by a single operator at working length using ProTaper ${ }^{\circledR}$ system (Dentsply Maillefer) and X-SmartTM endodontic micromotor Motor ${ }^{\circledR}$ (Dentsply, UK). After each instrument, the canals were irrigated using $5 \mathrm{~mL}$ of $2.5 \% \mathrm{NaOCl}$ solution.

The root canals obturation. Each tooth was endodontically obturated using gutta-percha in combination with one of the four sealers. The obturation method used was warm vertical condensation technique in apical third and injection of gutta-percha in the coronal two-thirds.

After complete setting, the samples were placed in resin blocks and then sectioned using a microtome (Buehler-IsoMet 1000) in slices with $1 \mathrm{~mm}$ thickness. Four samples from the apical third were selected for each tooth (two apical and two median) and were randomly distributed for SEM, AFM and push-out analysis.

Scanning electronic microscopy (SEM). All samples prepared for SEM analysis were immersed in $2.5 \%$ sodium hypochlorite for $1 \mathrm{~min}, 17 \%$ EDTA for $2 \mathrm{~min}$ and finally three times distilled water for 2 min (R. Espinar-type ultrasound bath (RAYPA)). A single examiner measured the highest gap width as the highest distance between root canal dentin and the sealer with a magnification of $\times 2000$.

The push-out test. Each slice of tooth was subjected to a constant force, by means of a cylinder-piston of $0.70 \mathrm{~mm}$ thick attached to a universal mechanical testing machine (Lloyd Instruments-LR5k plus). On the surface of the filler material, a constant load of $0.5 \mathrm{~mm} / \mathrm{min}$ was maintained until failure. Failure forces were recorded for each section of the tooth. The retention strength S (MPa) of the "monoblock system" of the tested tooth slice was calculated. Each tooth slice was numbered and examined on both sides, before and after the push-out test under the stereomicroscope (STEMI 2000 C Zeiss, Jena, Germany), at a magnification of $20 \times$. The bond strength values for all sealers were analyzed and compared using ANOVA statistical test and SPSS Statistic Software.

Atomical force microscopy (AFM). The images were obtained with a commercial Ntegra Spectra microscope (NT-MDT, Russia). After acquisition, the images were processed using Nova v1.1.0.1837 (NT-MDT). For each sample, the measurements were performed at the contact area, dentin-sealant. For the analysis of the interface, researchers used statistical 
parameters calculated for the image on which was applied the correction "fit lines" by which a second-degree polynomial is found and extracted for each scan line.

FTIR Spectroscopy evaluation. A Teflon mold was used to obtain 20 samples of the experimental materials (10 samples E1-DCR and 10 samples E2-HA) with the dimensions: diameter $\mathrm{d}=15 \pm 1 \mathrm{~mm}$ and thickness $\mathrm{h}=1 \mathrm{~mm}$. The samples were immersed in blood ( 5 samples E1-DCR and 5 samples E2-HA) and hemoglobin (5 samples E1-DCR and 5 samples E2-HA) for 42 days at $40^{\circ} \mathrm{C}$ and then incorporated in the resin so that they could be sliced. IR spectra were recorded using an FT-IR Spectrum BX spectrometer using an attenuated reflection (ATR) device.

Statistical analysis. Prior to statistical evaluation, Power analysis was performed to calculate adequate number of samples to be included in the study using G3*Power calculation software version 3.1.9.6. (Erdfelder, Faul, \& Buchner, 1996). From the results of similar study, it was observed that the expected mean values of bond strength would be around $1 \mathrm{MPa}$ with corresponding standard deviations around 0.4 [24]. These data gave us an estimated effect size $\mathrm{f}$ value of 0.25 that we used to calculate minimal necessary number of samples for one-way analysis of variance (ANOVA). For the twelve groups, with $\alpha$ level of probability of 0.05 and sample power of $90 \%$, we needed minimum 9 samples.

All data were collected and statistically analyzed using SPSS Statistics (ver. 20.0, Chicago, IL, USA). Two-way ANOVA was performed, Student-Newman-Keuls post-hoc test was done for pair-wise comparison and $p$ values $<0.05$ were considered statistically significant.

\section{Results}

\subsection{Scanning Electron Microscopy}

SEM analysis has allowed the identification and measure of gaps on dentinal wall/endodontic sealer interface and also the apical sealing ability.

SEM images have shown that the width of the E1-DCR material layer is lower than 10 microns, making this material suitable for the endodontic filling (Figure 2a).

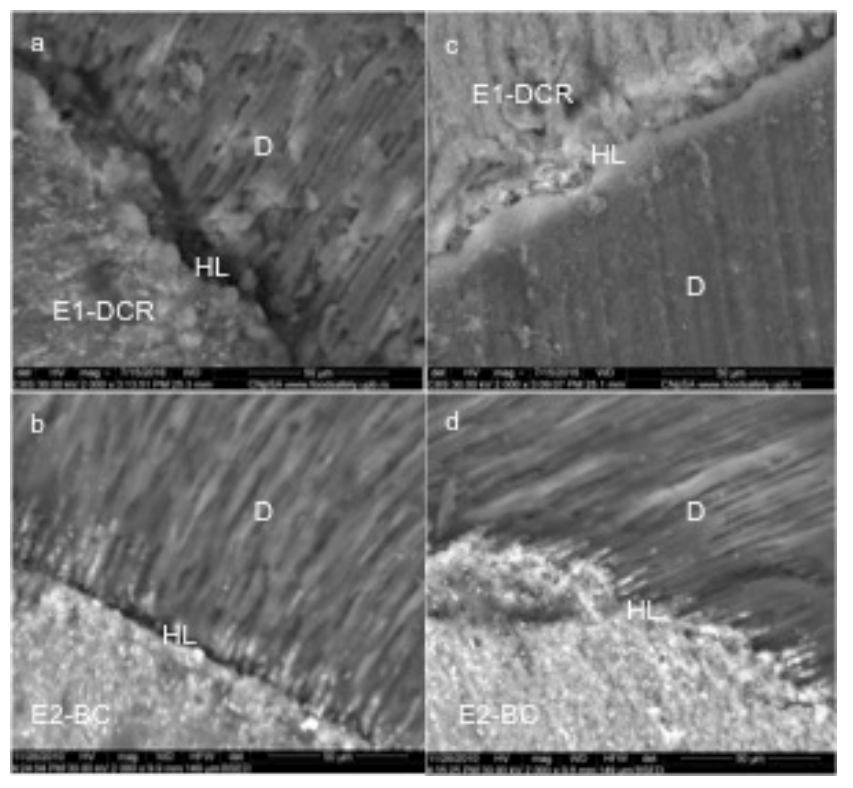

Figure 2. Representative SEM images of experimental sealers (magnification 2000X): dual cure resin experimental sealer E1-DCR $(\mathbf{a}, \mathbf{c})$; bioceramic experimental sealer E2-BC(b,d); HL-hybrid layer, D-dentin.

A high degree of homogeneity was also identified for the polymerized experimental E2-BC sealing material. The E2-BC sealant extensions that intersect the hybrid layer have a similar electron density with the overlying layer, which demonstrated a continuity of the 
concentration of bioceramic nanoparticles to depth. The periphery of the dentinal canals was "hybridized" and the hybrid layer obtained with this material extends over the entire depth of the demineralized area. In other words, the sealer mediated a complete adaptation between the dental structures and the gutta-percha (Figure $2 b$ ).

The E1-DCR sealant did not penetrate deep into the dentinal canals; SEM analysis showed that the non-adherent dentinal surfaces still had sealant residues and most of the orifices of the dentinal tubules were clogged, thus creating the conditions for mechanical retention and a satisfactory seal (Figure 2c).

The E1-DCR material does not present a significantly improved apical sealing ability when compared to the E2-BC material (Figure 2d).

The evaluation of the experimental materials using SEM has shown a homogenous layer on the apical region, with extensions intersecting the hybrid layer.

In case of RealSeal samples, dentinal tubules exposure and lower penetration of the sealing material was observed (Figure 3a).

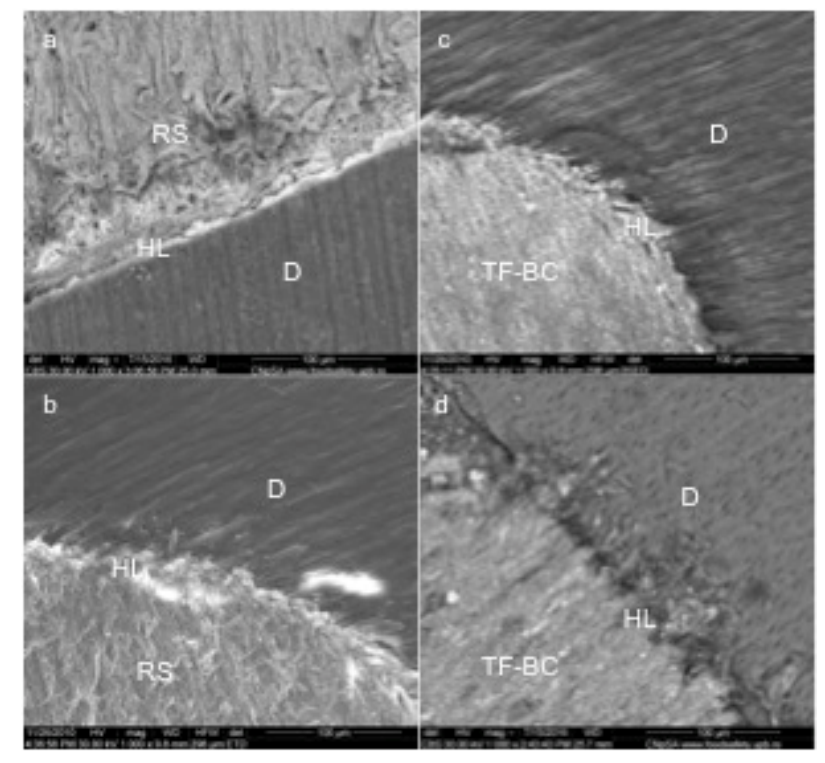

Figure 3. Representative SEM images of commercial sealers (magnification 1000X): Real Seal $(\mathbf{a}, \mathbf{b})$; TotalFill BC (c,d); RS- RealSeal, TF-BC- TotalFill BC, HL-hybrid layer, D-dentin.

Gaps were identified in case of RealSeal samples and also lower penetration into the dentinal tubules compared to TotalFill BC. 1 (Figure 3b,c).

\subsection{Atomic Force Microscopy}

Three-dimensional images obtained with AFM in the apical area show the homogenous surface structure of both experimental materials (Figure 4).

E1-DCR samples present a complex topography with smooth dentin and the sealing layer (Figure 4a). A high number of dentinal tubules are completely covered by the sealer with a maximum penetration depth of $2.8 \mu \mathrm{m}$. The profile line shows how the sealer appropriately moistens the edges of the dentinal tubules, reducing their diameter and forming a sealing foil.

In E2-BC samples the dentinal tubules are better highlighted and the sealing material structures are less visible (Figure $4 \mathrm{~b}$ ). This indicates a better flow of the pellicle, ensuring the surface homogeneity and also an improved penetration into the dentinal canals, up to $4.2 \mu \mathrm{m}$. 


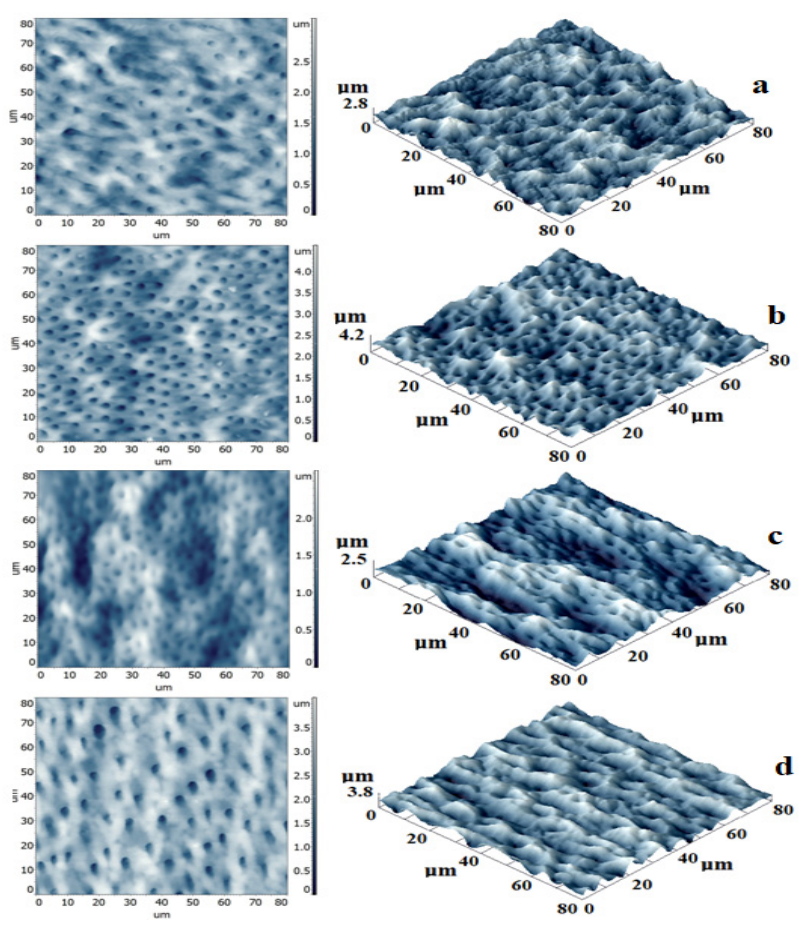

Figure 4. AFM images of sealer/dentin interface: bidimensional- left and tridimensional -right. (a)-E1-DCR, (b)-E2-BC, (c)-RS, (d)-TF-BC).

Figure $3 c$ shows results in case of RS samples, where the most significant canal diameter reduction was encountered. This can be correlated to a higher viscosity of the sealer, allowing the formation of a thicker layer and ensuring a better seal. The depth of penetration in this case had a mean value of $2.5 \mu \mathrm{m}$.

On tridimensional images in case of TF-BC samples, a topography with highlighted dentinal tubules surrounded by sealer was observed. The sealing was obtained with very low diameter reduction and higher penetration $(3.8 \mu \mathrm{m})$.

A significant statistical association was observed between the diameter of the dentinal tubules and the sealer width (Table 1). In case of resin-based endodontic materials (both experimental and commercial), a direct proportion was observed between the diameter of the dentinal tubules and the sealer width. In case of bioceramic-based materials, a reduced sealer width was observed, meaning a decreased penetration into the dentinal tubules.

Table 1. Atomic force microscopy values for dentinal tubules diameter and sealer width.

\begin{tabular}{|c|c|c|c|c|c|c|}
\hline \multirow[b]{2}{*}{ Sample } & \multirow[b]{2}{*}{ Minimum } & \multicolumn{2}{|c|}{ Dentinal Tubules Diameter, $\mu \mathrm{m}$} & \multirow[b]{2}{*}{ Mean } & \multirow[t]{2}{*}{ Sealer Width nm } & \multirow[t]{2}{*}{$p$} \\
\hline & & Intermediary & Maximum & & & \\
\hline E1-DCR & 1.45 & 2.90 & 3.87 & 2.47 & 125 & \\
\hline E2-BC & 2.03 & 3.05 & 3.39 & 2.82 & 85 & \\
\hline RS & 1.21 & 1.45 & 2.18 & 1.61 & 69 & 0.001 \\
\hline TF-BC & 1.69 & 3.05 & 3.92 & 2.88 & 55 & \\
\hline
\end{tabular}

\subsection{FTIR Spectroscopy}

The results obtained in the case of endodontic sealing cement E1-DCR determination of infrared absorption spectra are shown in Table 2. The difference between the spectra is insignificant; the relative intensities of absorption maxima are close in the case of the two samples (kept in blood and respectively in hemoglobin). Both ratios of absorption maxima are lower in the case of the sample kept in the blood, so it can be concluded that the interaction with the blood was stronger than the interaction with the hemoglobin in 
the case of E1-DCR. On the other hand, there is a shift of the absorption maxima towards higher wave numbers in the case of the sample stored in hemoglobin.

Table 2. Absorption maximum intensity values considered for estimating the interaction of composite materials with media containing blood and hemoglobin.

\begin{tabular}{cccccc}
\hline Sample & I C $\mathbf{~ O ~} \sim \mathbf{1 7 1 7} \mathbf{~ c m}^{-\mathbf{1}}$ & $\mathbf{I} \mathbf{C}=\mathbf{C} \sim \mathbf{1 6 3 6} \mathbf{~ m}^{\mathbf{- 1}}$ & $\mathbf{I} \mathbf{~ S i - O - S i ~} \mathbf{1 0 4 0} \mathbf{~ c m}^{-\mathbf{1}}$ & $\mathbf{I} \mathbf{C}=\mathbf{O} / \mathbf{I} \mathbf{C}=\mathbf{C}$ & $\mathbf{I} \mathbf{~ S i - O - S i} / \mathbf{I} \mathbf{C}=\mathbf{C}$ \\
\hline E1-DCR hemo & 0.0321 & 0.0076 & 0.12 & 4.223684211 & 15.78947 \\
E1-DCR blood & 0.0362 & 0.0093 & 0.119 & 3.892473118 & 12.7957 \\
E2-BC hemo & 0.1426 & 0.0362 & 0.2991 & 3.939226519 & 8.262431 \\
E2-BC blood & 0.1673 & 0.0207 & 0.2534 & 8.082125604 & 12.24155 \\
Control H & 0.169 & 0.0207 & 0.1965 & 8.164251208 & 9.492754 \\
Control B & 0.2385 & 0.0367 & 0.2743 & 6.498637602 & 7.474114 \\
\hline
\end{tabular}

In the case of the E2-BC material, both ratios are higher in the case of the sample kept in the blood, so it can be concluded that the interaction of the sealer with the blood was weaker, leading to the modification of a smaller number of connections in the endodontic material. Regarding the absorption maxima, in the case of samples kept in the blood, a small displacement (maximum $1 \mathrm{~cm}^{-1}$ ) of the absorption maxima towards higher wave numbers is observed. The maxima are more pronounced for the sample stored in hemoglobin, which suggests that the bonds in which silica is involved are less affected.

In the case of control samples, the interaction with both hemoglobin and blood was reduced, the values obtained for the ratio of intensities considered for comparison being insignificant.

The intensity of the bands associated with the urethane monomer indicates a good diffusion of the monomer resin in the demineralized area of the dentin, which is an indication of the affinity of the monomer to the dental structure, which justifies its consideration as a potential monomer in formulating an efficient dental endodontic material in E1-DCR experimental material.

\subsection{Push-Out Test}

The values of mean bond strength in the apical and median areas are presented in Table 3. The only statistical significance was observed when compared in the apical area E1-DCR and Total Fill BC $(p=0.01)$.

Table 3. Mean bond strength of the four materials.

\begin{tabular}{ccccc}
\hline \multicolumn{5}{c}{ Mean Bond Strength (MPa) } \\
\hline Sample & Median & $p$ & Apical & $p$ \\
\hline E2-BC & $0.9322 \pm 0.25$ & 0.7 & $1.3096 \pm 0.01$ & \multirow{2}{*}{0.09} \\
RS & $1.0062 \pm 0.90$ & & $0.6524 \pm 0.43$ & \\
\hline TF-BC & $1.4367 \pm 1.05$ & \multirow{2}{*}{0.3} & $2.4524 \pm 1.15$ & \multirow{2}{*}{0.01} \\
E1-DCR & $0.8294 \pm 0.18$ & & $0.7177 \pm 0.55$ & \\
\hline
\end{tabular}

Regarding the interface where the failure occurred (sealer/dentin or sealer/guttapercha), we observed a good adhesion to dentin for all the materials. So, for the Total Fill BC, $80 \%$ of the samples failed at the interface of the sealer/gutta-percha or inside of gutta-percha cone. For Real Seal, $72.5 \%$ of the samples had similar failures, E1-DCR $77.5 \%$ and $\mathrm{E} 2-\mathrm{BC} 78.5 \%$. On average, $40 \%$ of these failures were inside the core material (gutta-percha) or combined failures (Figure 5). 


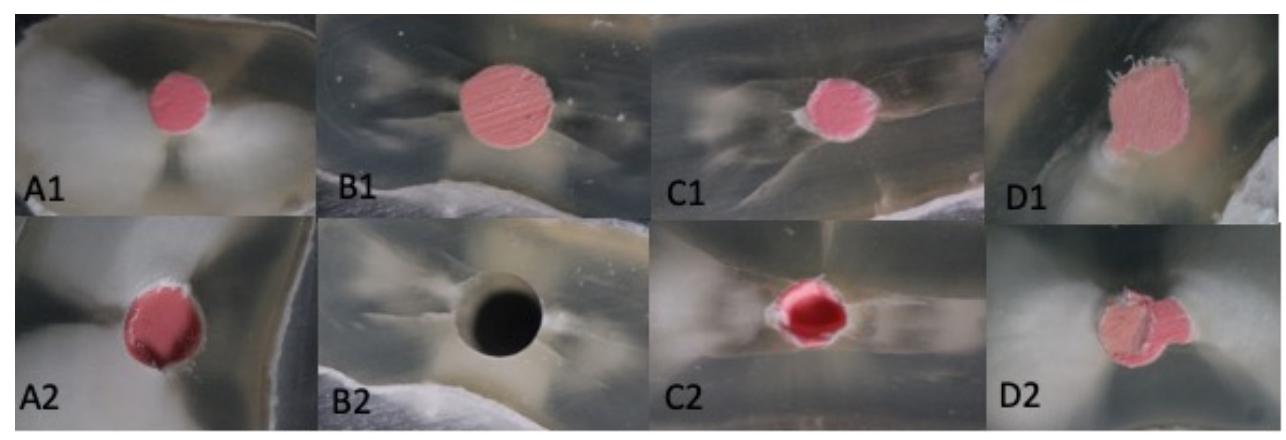

Figure 5. Initial situation (A1-D1), Gutta-percha/sealer interface failure- E2-BC (A2), Dentin/sealer interface failure E1-DCR (B2), Core material failure-gutta-percha (C2)-Real Seal, (D2)-Total Fill BC).

\section{Discussion}

Adhesion to the dentinal walls of the root canal has been and continues to be the subject of many research topics. Studies on micro infiltration, using different methods of determination, have led to contradictory results, some unfavorable, others favorable. In addition to the issue of micro infiltration, the ability of the tooth to adapt to physiological conditions through a dynamic status of the sealer-dentin interface must be taken into account $[25,26]$.

SEM and AFM images obtained in the present study showed a more profound penetration into the dentinal tubules for the bioceramic based sealers (both commercial (TotalFill $\mathrm{BC}$ and $\mathrm{E} 2-\mathrm{BC})$. Meanwhile, hydroxyapatite-based sealers have a thinner layer on the interface with the dental structures. The formation of a homogeneous hybrid layer was present in case of all materials, ensuring the closure of any communication path between the root canal and the outside, thus achieving a sealing of the dentinal wound. The E1DCR material has a composition that allows it to infiltrate the demineralized dentinal structure and succeeds in forming this layer. The failure of its formation means allowing the communication between the endodontic space and the periodontal or oral environment, with the appearance of marginal infiltration [27]. Thus, a communication pathway is created for bacteria, which will colonize the endodontic space in this way. At the same time, water is allowed to enter, which will lead to the hydrolytic degradation of the cement and the connections formed between it and the dental tissues [28].

Liviu Steier and collaborators carried out a study comparing the dentin-sealant interface for two commercial sealants: RealSeal and AH Plus at two magnification orders $(\times 150$ and $\times 1000)$ using a scanning electron microscope $(\mathrm{SEM})$. They concluded that there are fewer gaps in the dentin/RealSeal interface than in the dentin/AH Plus interface [27].

The formation of the hybrid layer in case of E2-BC sealer is favored by the existence of hydrophilic monomers and of the solvent that the sealer contains. It is well known that it is impossible to completely remove extrinsic wastewater from root canal spaces. As the components of the bioceramic material enable the formation of calcium hydroxide and hydroxyapatite, they ensure an excellent bond to both the dentin and the filling material. Meanwhile they allow the practitioner to perform the microbial control without removing dentin unnecessarily and leaving a stronger root for restorative reconstruction [22]. A problem with hardening of premixed bioceramic sealers could be the lack of moisture in the root canal system, especially in already endodontically treated teeth [26].

Total Fill BC (FKG, Germany) is a bioceramic sealer recognized for its biological properties such as biocompatibility, bioactivity and antibacterial activity as well as for its excellent physic-chemical properties. Unlike conventional filling cements, the setting reaction of Total Fill BC (FKG, Germany) is triggered by the moisture present in the dentinal tubules. Using this moisture, Total Fill BC sealer forms hydroxyapatite, to ensure optimum chemical adhesion between the dentin and the cement [29].

The bond strength of root canal sealers to dentin is important for maintaining the integrity of the seal in root canal filling in both static and dynamic situations. In a static 
situation, it should eliminate any space that allowed the percolation of fluids between the filling and the wall; in a dynamic situation, it was needed to resist dislodgement of the filling during subsequent manipulation [13].

In this study, the push-out test method was used to test the dentin bond strengths of different root canal sealers; the model had been shown to be effective and reproducible. Another advantage of this method is that it allowed root canal sealers to be evaluated even when bond strengths are low.

At the apical area, the E2-BC sealer had the highest mean bond strength. In descending order TotallFill BC, E1-HA and Real Seal followed. In the median area, the E1-HA sealer had the lowest mean bond strength and TotallFill the highest bond strength. Regarding TotallFill BC and RealSeal, the results are consistent with the results obtained by Mishra et al. [21].

In our study the obturation method used was warm vertical condensation technique in apical third and injection of gutta-percha in the coronal two-thirds. The heat generated during the filling technique can influence sealers characteristics. Previous studies on bioceramic endodontic sealers have reported that the chemical composition has not changed after heating [30,31]. In addition, bioceramic sealer EndoSequence BC Sealer HiFlow (Brasseler USA, Savannah, GA, USA) underwent an improvement in flow, viscosity, and film thickness after heating [32].

The heat generated by the injected gutta-percha in the median area could explain the variations that occurred in the case of the E1-DCR sealer. Lawson et al. concluded that the evaporation of the liquid resin component of the sealer by heat generated during obturation technique could result in a highly viscous sealer that had a limited flow capacity into the patent dentinal tubules and lower bond strength; in addition, the rate of polymerization may be accelerated by heat and increase shrinkage and decrease bond strength [33].

Another explanation for the lower bond strengths at sealer/dentin interface detected in the groups containing a methacrylate resin-based sealer is the effect of cavity configuration factors (C-Factor: the ratio bonded to unbounded surface). Methacrylate resin-based sealers present greater $\mathrm{C}$-factor, causing more polymerization shrinkage and hence more gap formation and micro-leakage [34].

A significant expansion of $0.20 \%$ of TotalFill BC Sealer also determines the disappearance of gaps on sealer/root canal interface, which makes the sealer more effective, with higher strength bond [35].

The environmental conditions affect the hydration of the bioceramic-based sealers and consequentially the material interaction with the environment. However, in vitro material assessment may not be representative of the clinical situation because carbon dioxide present in vivo leads to the formation of calcium carbonate rather than the hydroxyapatite reported in in vitro studies [36].

It is well-known that bioactive glasses have excellent biocompatibility. The $\mathrm{SiO}_{2}-\mathrm{CaO}$ glass with a range of $50-90 \mathrm{~mol} \% \mathrm{SiO}_{2}$ in the system was bioactive and formed an apatite layer in simulated body fluid. The bioactivity of the sol-gel bioglass nanoparticles with high silica contents is related to the broad distribution of the bonding network between the oxygen and silicon atoms [37].

The appearance of new absorption bands in the BAG and HA-containing sealers at $\sim 1400 \mathrm{~cm}^{-1}$ can be assigned to $\mathrm{C}-\mathrm{O}$ stretching vibration and therefore to the formation of carbonated apatite that mimics the apatite of bone and dental hard tissues. Some studies determined that the apatite layer formation on the surface of composites reinforced with HA fillers in the SBF solution may resulted from the dissolution of HA particles which can lead to the supersaturation of $\mathrm{Ca}^{2+}$ and $\mathrm{PO}_{4}{ }^{3-}$ and promote the nucleation and growth of HA crystals [38].

\section{Conclusions}

The preliminary results of the current in-vitro study have indicated that the dual cure resin experimental material has high potential for practical applicability, showing good results from preclinical point of view. At the same time, the bioceramic experimental sealer 
has shown better penetration into the dentinal tubules forming a more consistent hybrid layer due to its hydrophilic character. Within the limitations of the current study, it can be stated that the two experimental sealers' characteristics are comparable to that of the two consecrated materials.

Author Contributions: Conceptualization, R.M.C., A.M.C., M.P. and M.M.; methodology, A.G.D., R.M.C., D.H., D.P. and O.P.; software, A.M. and D.I.R.; validation, R.M.C., A.M.C. and M.M.; formal analysis, A.M.; investigation, D.H., A.M. and O.P.; resources, M.M., R.M.C. and M.P.; data curation, D.P., A.G.D., D.I.R. and M.P.; writing—original draft preparation, D.I.R., M.P. and A.M.C.; writingreview and editing, A.M.C., R.M.C. and A.G.D.; visualization, R.M.C. and A.M.C.; supervision, R.M.C. and M.P.; project administration, M.M.; funding acquisition, O.P., R.M.C., A.G.D. and A.M. have equal contribution to the current study. All authors have read and agreed to the published version of the manuscript.

Funding: This research received no external funding.

Institutional Review Board Statement: Not applicable.

Informed Consent Statement: Not applicable.

Conflicts of Interest: The authors declare no conflict of interest.

\section{References}

1. Tay, F.R.; Loushine, R.J.; Lambrechts, P.; Weller, R.N.; Pashley, D.H. Geometric factors affecting dentin bonding in root canals: A theoretical modeling approach. J. Endod. 2005, 31, 584-589. [CrossRef] [PubMed]

2. Carvalho, R.M.; Pereira, J.C.; Yoshiyama, M.; Pashley, D.H. A review of polymerization contraction: The influence of stress development versus stress relief. Oper. Dent. 1996, 21, 17-24. [PubMed]

3. Hrab, D.; Pastrav, O.; Chisnoiu, R.; Prodan, D.; Badea, M.E.; Chisnoiu, A. The effectiveness of photodynamic therapy in endodontic sealer adhesion. JOAM 2016, 18, 899-903.

4. Lohbauer, U.; Nikolaenko, S.A.; Petschelt, A.; Frankenberger, R. Resin tags do not contribute to dentin adhesion in self-etching adhesives. J. Adhes. Dent. 2008, 10, 97-103. [PubMed]

5. $\quad$ Oliveira, S.S.; Pugach, M.K.; Hilton, J.F.; Watanabe, L.G.; Marshall, S.J.; Marshall, G.W., Jr. The influence of the dentin smear layer on adhesion: A self-etching primer vs. a total-etch system. Dent. Mater. 2003, 19, 758-767. [CrossRef]

6. Reis, A.; Grandi, V.; Carlotto, L. Effect of smear layer thickness and acidity of selfetching solutions on early and long-term bond strength to dentin. J. Dent. 2005, 33, 549-559. [CrossRef] [PubMed]

7. Babb, B.R.; Loushine, R.J.; Bryan, T.E. Bonding of self-adhesive (self-etching) root canal sealers to radicular dentin. J. Endod. 2009, 35, 578-582. [CrossRef]

8. Miyasaka, K.; Nakabayashi, N. Combination of EDTA conditioner and phenyl-P/HEMA self-etching primer for bonding to dentin. Dent. Mater. 1999, 15, 153-157. [CrossRef]

9. Chisnoiu, R.; Moldovan, M.; Chisnoiu, A.; Hrab, D.; Rotaru, D.; Păstrav, O.; Delean, A. Comparative apical sealing evaluation of two bioceramic endodontic sealers. Med. Pharm Rep. 2019, 92, S55-S60. [CrossRef]

10. Best, S.M.; Porter, A.E.; Thian, E.S.; Huang, J. Bioceramics: Past, Present and for the Future. J. Eur. Ceram. Soc. 2008, 1, $1319-1327$. [CrossRef]

11. Moldovan, M.; Prejmerean, C.; Colceriu, A.; Tamas, C.; Furtos, G.; Prodan, D.; Trif, M.; Alb, C.; Neamt, S.; Popescu, V. Effect of coupling agents on the local mechanical properties of bioactive dental composites. JOAM 2007, 9, 3415.

12. Gurgel-Filho, E.D.; Lima, F.C.; Saboia, V.D.P.A.; de Souza Coutinho-Filho, T.; de Almeida Neves, A.; da Silva, E.J. Push-out bond strength of a self-adhesive resin cement used as endodontic sealer. Restor. Dent. Endod. 2014, 39, 282-287. [CrossRef]

13. Mohammadian, F.; Farahanimastary, F.; Dibaji, F.; Kharazifard, M.J. Scanning Electron Microscopic Evaluation of the SealerDentine Interface of Three Sealers. Iran. Endod. J. 2017, 12, 38-42.

14. Ballullaya, S.V.; Vinay, V.; Thumu, J.; Devalla, S.; Bollu, I.P.; Balla, S. Stereomicroscopic Dye Leakage Measurement of Six Different Root Canal Sealers. J. Clin. Diagn. Res. 2017, 11, ZC65-ZC68. [CrossRef]

15. Chisnoiu, R.; Moldovan, M.; Păstrav, O.; Delean, A.; Chisnoiu, A.M. The influence of three endodontic sealers on bone healing: An experimental study. Folia Morphol. 2016, 75, 14-20. [CrossRef]

16. Van Meerbeeck, B.; Vargas, M.; Ionue, S. Microscopy investigations: Techniques, results, limitations. Am. J. Dent. 2000, 13, 3-18.

17. Zhang, W.; Li, Z.; Peng, B. Assessment of a new root canal sealer's apical sealing ability. Oral Surg. Oral Med. Oral Pathol. Oral Radiol. Endod. 2009, 107, 79-82. [CrossRef]

18. Kim, Y.K.; Grandini, S.; Ames, M.; Gu, L.S.; Kim, S.K.; Pashley, D.H.; Gutmann, J.L.; Tay, F.R. Critical Review on Methacrylate Resin-based Root CanalSealers. J. Endod. 2010, 36, 383-399. [CrossRef]

19. Ayad, M.F.; Bahannan, S.A.; Rosenstiel, S.F. Morphological characteristics of the interface between resin composite and glassionomer cement to thin-walled roots; A microscopic investigation. Am. J. Dent. 2010, 23, 103-107.

20. Trache, A.; Meininger, G.A. Atomic force microscopy (AFM). Curr. Protoc. Microbiol. 2008, 2, C2. [CrossRef] 
21. Mishra, P.; Sharma, A.; Mishra, S.; Gupta, M. Push-out bond strength of different endodontic obturation material at three different sites in-vitro study. J. Clin. Exp. Dent. 2017, 9, e733-e737. [CrossRef]

22. Candeiro, G.T.; Correia, F.C.; Duarte, M.A.; Ribeiro-Siqueira, D.C.; Gavini, G. Evaluation of radiopacity, pH, release of calcium ions, and flow of a bioceramic root canal sealer. J. Endod. 2012, 38, 842-845. [CrossRef]

23. Chisnoiu, R.; Pastrav, O.; Delean, A.; Prodan, D.; Boboia, S.; Moldovan, M.; Chisnoiu, A. Push-out Bond Strengths of Three Different Endodontic Sealers A comparative study. Mat. Plast. 2015, 6, 239-242.

24. Yap, W.Y.; Ab Aziz, Z.A.C.; Azami, N.H.; Al-Haddad, A.Y.; Khan, A.A. An in vitro Comparison of Bond Strength of Different Sealers/Obturation Systems to Root Dentin Using the Push-Out Test at 2 Weeks and 3 Months after Obturation. Med. Princ. Pract. 2017, 26, 464-469. [CrossRef]

25. Monticelli, F.; Osorio, R.; Mazzitelli, C.; Ferrari, M.; Toledano, M. Limited decalcification/ diffusion of self-adhesive cements into dentin. J. Dent. Res. 2008, 87, 74-979. [CrossRef]

26. Zmener, O.; Pameiher, C.H.; Serrano, S.A.; Vidueira, M.; Macchi, R.L. Significance of moist root canal dentin with the use of methacrylate-based endodontic sealers: An in vitro coronal dye leakage study. J. Endod. 2008, 34, 76-79. [CrossRef]

27. Steier, L.; Figueiredo, J.A.; Belli, S. Comparison of the interface dentin-endodontic sealer using two SEM magnifications. Rev. Odonto Cienc. 2010, 25, 296-299. [CrossRef]

28. Mukhtar-Fayyad, D. Cytocompatibility of new bioceramic-based materials on human fibroblast cells (MRC-5). Oral Surg. Oral Med. Oral Pathol. Oral Radiol. Endod. 2011, 112, e137-e142. [CrossRef]

29. Zhang, W.; Li, Z.; Peng, B. Ex vivo cytotoxicity of a new calcium silicate-based canal filling material. Int. Endod. J. 2010, 43, 769-774. [CrossRef]

30. Santos-Junior, A.O.; Tanomaru-Filho, M.; Pinto, J.C.; Tavares, K.I.M.C.; Torres, F.F.E.; Guerreiro-Tanomaru, J.M. Effect of obturation technique using a new bioceramic sealer on the presence of voids in flattened root canals. Braz. Oral Res. 2021, 35, e028. [CrossRef]

31. Atmeh, A.R.; AlShwaimi, E. The effect of heating time and temperature on epoxy resin and calcium silicate-based endodontic sealers. J. Endod. 2017, 43, 2112-2118. [CrossRef] [PubMed]

32. Chen, B.; Haapasalo, M.; Mobuchon, C.; Li, X.; Ma, J.; Shen, Y. Cytotoxicity and the effect of temperature on physical properties and chemical composition of a new calcium silicate-based root canal sealer. J. Endod. 2020, 46, 531-538.

33. Lawson, M.S.; Loushine, B.; Mai, S. Resistance of a 4-META- containing, methacrylate-based sealer to dislocation in root canals. J. Endod. 2008, 34, 833. [CrossRef] [PubMed]

34. Zhou, H.M.; Shen, Y.; Zheng, W.; Zheng, Y.; Haapasalo, M. Physical properties of 5 root canal sealers. J. Endod. 2013, 39, 1281.e6. [CrossRef]

35. Zoufan, K.; Komabayashi, T.; Safavi, K.E.; Zhu, Q. Cytotoxicity evaluation of Gutta Flow and Endo Sequence BC sealers. Oral Surg. Oral Med. Oral Pathol. Oral Radiol. Endod. 2011, 112, 657-661. [CrossRef]

36. Al-Bakhsh, B.A.J.; Shafiei, F.; Hashemian, A.; Shekofteh, K.; Bolhari, B.; Behroozibakhsh, M. In-vitro bioactivity evaluation and physical properties of an epoxy-based dental sealer reinforced with synthesized fluorine-substituted hydroxyapatite, hydroxyapatite and bioactive glass nanofillers. Bioact. Mater. 2019, 4, 322-333. [CrossRef]

37. Lin, X.Y.; Fan, H.S.; Li, X.D.; Tang, M.; Zhang, X.D. Evaluation of bioactivity and cytocompatibility of nano-hydroxyapatite/collagen composite in vitro. Key Eng. Mater. 2005, 284, 553-556. [CrossRef]

38. Korkut, E.; Torlak, E.; Altunsoy, M. Antimicrobial and mechanical properties of dental resin composite containing bioactive glass. J. Appl. Biomater. Funct. Mater. 2006, 14, e296-e301. [CrossRef] 